\title{
Effect of p53 Codon 72 Polymorphism on Clinical Outcome in Lo- cally Advanced Breast Cancer Patients Receiving Anthracycline Based Neoadjuvant Chemotherapy
}

\author{
Sambasivam Gopinath ${ }^{* 1}$, Deepak Gopal Shewade ${ }^{1}$, Biswajit Dubashi ${ }^{2}$, Dharanipragada Kadambari ${ }^{3}$, Ananthakrishnan Ramesh ${ }^{4}$, Rama- \\ samy Kesavan ${ }^{1}$ \\ 'Department of Pharmacology, JIPMER, Puducherry, INDIA \\ 2Department of Medical oncology, JIPMER, Puducherry, INDIA. \\ ${ }^{3}$ Department of Surgery, JIPMER, Puducherry, INDIA. \\ ${ }^{4}$ Department of Radio Diagnosis, JIPMER, Puducherry, INDIA.
}

\begin{abstract}
Background: Breast cancer is the second most common cancer in the world after lung cancer and the most common cancer among women. Most of the women exhibit interindividual variation to cytotoxic therapy. It may be due to the genetic polymorphism of genes involved in pharmacokinetics and pharmacodynamics pathways of drugs. Various studies implicated the role of p53 gene polymorphism in the sensitivity of apoptosis. Objective: The objective of the study was to know the effect of p53 tumor suppressor gene 72 codon polymorphism on response in breast cancer patients receiving anthracycline-based neoadjuvant chemotherapy. Results: A total of 170 patients were enrolled for the study. The median age of the patient group was 50 year (23-60). The majority of patients were post-menopausal (61\%). Most of the patients were node positive and also found to have grade II tumor. Hormone receptor positivity of estrogen, progesterone, and human epidermal growth factor were $48 \%, 37 \%$, and $60 \%$. The genotype of 72 $\mathrm{G}>\mathrm{C}$ codon polymorphism was done by real time-polymerase chain reaction The frequencies of wild homozygous variant $\mathrm{GG}$, heterozygous variant GC, and mutant homozygous variant CC were found to be $42 \%, 43 \%$, and $15 \%$ respectively. 145 patients were assessed for response of which 133 patients were found be responders and 12 patients were found be non-responders. The genotype frequency of $\mathrm{P} 5379 \mathrm{G}>\mathrm{A}$ variant were significantly
\end{abstract}

different between patients having a complete and partial response in the recessive genetic model $(R R=0.2972, C . I=0.078-1.122, P=0.03$.). However there was no association of genotypes with progression-free survival and overall survival. Conclusion: This study concludes that p53 gene polymorphism partially may have a role in predicting the response in breast cancer patients.

Key words: p53 tumor suppressor gene, Single nucleotide polymorphism, Anthracyclines, Tumor response, Pathological response.

\section{Correspondence}

Gopinath Sambasivam

PhD scholar, Department of Pharmacology, JIPMER, Puducherry-605006,

INDIA.

Phone no: 9488117306

E-mail: gopimbapharma@gmail.com

DOI: 10.5530/jyp.2017.9.21

\section{INTRODUCTION}

In India, breast cancer accounts for $5-8 \%$ of all cancers, and there is an increase in incidence every year. It is the most prevalent cancer in urban Indian women and the second most common in rural women. India reports roughly 100000 new cases per year and incidence rates have been increasing by up to $5 \%$ per year. ${ }^{1,2}$ The introduction of neoadjuvant chemotherapy in the management of breast cancer was very useful to the patients because previously inoperable tumors are amenable to surgery, and it helps in retaining the control of existing systemic disease. Most of the patients up to $50 \%$ of women receiving preoperative cytotoxic therapy do not respond to the treatment. ${ }^{3,4}$ The clinical response to neoadjuvant chemotherapy is mostly imprecise and not an accurate reflection of the pathologic response. ${ }^{5}$ Studies reported patients having the complete pathological response after neoadjuvant chemotherapy have a significant longer progression-free and overall survival. ${ }^{6,7}$ So identification and establishment of genetic markers predictive of patient responses will result in improved survival rates and also prevents toxic effects of cytotoxic therapy due to better selection of dose and drugs. Anthracycline-based regimens are widely prescribed for neoadjuvant chemotherapy in breast cancer patients. Anthracyclines like doxorubicin, epirubicin, daunoru- bicin as well as alkylating substances (cyclophosphamide) induce DNA damage. It leads to apoptosis due to p53 activation. ${ }^{8}$ The biological functions of the 53 tumor suppressor gene are much wider which makes it a potential predictive marker for tumor response. P53 mainly functions as a transcription factor by regulating normal cell growth by controlling genes that promote progression and also controls the genes that cause arrest in G1 when the genome is damaged. ${ }^{9}$ Activation of p53 can further promote apoptosis in growth-arrested cells and helps in execution of programmed cell death in response to DNA damage. Some studies have been undertaken to study the usefulness of p53 as a predictive factor in cancer patients. ${ }^{10,11}$ Among the variants in p53 gene p53 72 codon polymorphism (rs1042522) was extensively studied. ${ }^{12}$ The p53 tumor suppressor gene has 11 exons, located on chromosome 17p13. The codon 72 polymorphism is located in exon 4 with a C-C-C encoding proline or C-G-C encoding arginine Arg72Pro. ${ }^{13}$ These functional differences between the polymorphic variants may alter the tumor response to systemic chemotherapy by influencing the apoptotic capacity. Although some of the studies ${ }^{14,15}$ have reported that $\mathrm{p} 53$ codon 72 polymorphism may affect cancer risk for certain types of tumor, only limited studies carried out to show the predictive value of this polymorphism for tumor response to neoadjuvant chemotherapy. In this study, we hypothesize 
that the p53 codon 72 polymorphism may influence the clinical outcome of the anthracycline-based neoadjuvant treatment of South Indian breast cancer patients.

\section{MATERIALS AND METHODS}

\section{Study population}

After obtaining the institute ethics committee approval patients were recruited between January 2013 and June 2014 in the outpatient department of medical oncology, Jawaharlal Institute of Post-graduate Medical Education and Research, Puducherry. All newly diagnosed breast cancer patients were screened. Patients with locally advanced breast cancer who were going to receive anthracycline and taxane-based neoadjuvant chemotherapy were included in this study. Patients, having metastasis, male breast cancer patients, contraindications for chemotherapy and known allergy to iodine-based contrast materials were excluded. For the confirmation of the diagnosis in patients, fine-needle aspiration cytology and core needle biopsy were done. Patients were given the verbal explanation about their disease and the drugs prescribed to them. All patients who gave informed consent voluntarily were included in the study.

\section{Treatment protocol and end points}

Staging locally advanced breast carcinoma was done as per American Joint Committee on Cancer (AJCC). Patients with stage IIB (T3 N0 M0) stage IIIA and stage IIIB tumors were included in this study. Locally advanced breast cancer patients treated with either AC doxorubicin $60 \mathrm{mg}$ / $\mathrm{m}^{2}$, cyclophosphamide $600 \mathrm{mg} / \mathrm{m}^{2}$ ) for 4 cycles once every 3 weeks followed by docetaxel $100 \mathrm{mg} / \mathrm{m}^{2}$ for 4 cycles once every 3 weeks or FEC (5-fluorouracil $500 \mathrm{mg} / \mathrm{m}^{2}$, epirubicin $100 \mathrm{mg} / \mathrm{m}^{2}$, cyclophosphamide $500 \mathrm{mg} / \mathrm{m}^{2}$ ) for 3 cycles once every 3 weeks followed by Docetaxel 75 $\mathrm{mg} / \mathrm{m}^{2}$ for 4 cycles once every 3 weeks. Primary GCSF prophylaxis was given for patients receiving docetaxel at the dose of $100 \mathrm{mg} / \mathrm{m}^{2}$ and secondary GCSF was given if required for all other patients. Patients underwent MRI scan of the breast before the first cycle of chemotherapy and after the completion of chemotherapy. Tumour response was assessed using Response Evaluation Criteria in Solid Tumors (RECIST) criteria based on MRI scan. Progression-free survival is defined as the time since the start of treatment to the occurrence of the first event. Overall survival is defined as time since diagnosis of disease to death.

\section{DNA Extraction and Genotyping}

From the recruited patients $5 \mathrm{ml}$ of blood was collected in the tubes containing ethylenediaminetetraacetic acid (EDTA) as the anticoagulant for the extraction of DNA. Blood was centrifuged at $3000 \mathrm{~g}$, and supernatant plasma was discarded. The leukocytes were separated and subjected to DNA extraction by phenol-chloroform method. The extracted DNA was quantified using bio photometer (Eppendorf AG 22331, Germany). Genotyping was carried out by real-time PCR (7300 Applied Biosystems; Life Technologies Corporation, USA) using TaqMan SNP genotyping assays [Assay id: C___2403545_10].The version 1.4 of 7300 sequence detection software (SDS) was used for allelic discrimination.

\section{Statistical Analysis}

The observed genotype frequencies were tested for Hardy-Weinberg Equilibrium (HWE) by using the chi-square test. The association of polymorphic variant of p53 $72 \mathrm{G}>\mathrm{C}$ and response to neoadjuvant chemotherapy were analysed by calculating the relative risk and $95 \%$ confidence intervals (CIs) using the 2-tailed Fisher exact test. Survival analysis of patients were done by plotting Kaplan-Meier curves for progression free survival and overall survival among the genotypes. The log-rank test was used to assess for statistical significance of the effect of genotypes on progression free survival and overall survival. For the estimation of the hazard ratio (HR) with 95\% confidence interval (C.I) univariate cox regression analysis was used. Statistical analysis of data was performed using GraphPad Instat 3 (GraphPad Software Inc., San Diego, CA, USA) and SPSS software (version 16). $\mathrm{P}<0.05$ was considered significant.

\section{RESULTS}

\section{Patient and tumor characteristics}

Between January 2013 and June 2014, a total of a 176 locally advanced breast cancer patients were enrolled into the study. Of these six patients were ineligible, which include three patients had organ dysfunction (Cardiac-2 and renal-1), and three patients had metastasis. After excluding these six patients, a total of 170 patients were included in the analysis. The median age of the patient group was 50 year (23-60). The clinicopathological characteristics across genotypes are summarized in Table 1.

\section{Primary tumor and pathological response to neoadjuvant chemotherapy}

145 patients were assessed for response using RECIST criteria. 25 patients MRI could not done.45 patients (31\%) showed completed response, eighty-eight patients $(60 \%)$ had a PR, and 12 patients $(9 \%)$ had no response. Thus, objective response using RECIST criteria was $91 \%$. Of the 170 patients, 152 (89\%) patients underwent surgery. A total of 18 patients did not undergo surgery. Forty eight patients had a pCR in the study group. Pathological complete response (pCR) was seen in $32 \%$ in patients who underwent surgery.

\section{Genotyping and association with response}

The effect of genotypes on response of the patients were assessed by Fisher's exact test. The genotype frequency of p53 72G $>$ A variant were not significant between responders and non-responders and also in dominant and recessive genetic model (Table 2). However, the genotype frequencies of p53 72G $>$ A variant were significantly different between patients having the complete and partial response in the recessive genetic model ( $\mathrm{RR}=0.2972$, C.I $=0.078-1.122, \mathrm{P}=0.03$ (Table 3 )). In our study similarly comparing the patients having complete pathological response and not achieving the complete pathological response in both genetic models were not found to be significantly different (Table 4).

\section{Survival analysis}

Patients with homozygous wild genotype (GG), heterozygous mutant genotype (GC) and homozygous mutant genotype (CC) had a mean progression free survival (PFS) time of 33 months, 30 months and 31 months respectively. ( $\mathrm{HR}=1.15,95 \% \mathrm{CI}=0.83$ to $1.58, \mathrm{p}=0.422$ Figure 1) and overall survival (OS) time of 35.7 months 33.3 months and 35.1 months $(\mathrm{HR}=1.12,95 \% \mathrm{CI}=0.76$ to $1.62, \mathrm{p}=0.58$ Figure 2$)$. There was no significant difference in PFS and OS time between genotypes.

\section{DISCUSSION}

The importance of genetic makeup of the patients in the pharmacotherapy of cancer is widely accepted. Breast cancer is heterogeneous disease and has a lot of subtypes which responds to chemotherapy differently. So understanding the nature of the tumor characteristic along with the genetic information of patients were important. Several studies suggest that the $\mathrm{p} 53$ codon 72 polymorphism substantially controls p53dependent apoptotic activity. ${ }^{16,19}$ It was reported that the wild-type p53GG genotype is more efficient in inducing apoptosis than the mutant p5372-CC genotype. ${ }^{16}$ So we have investigated the effect of p53 codon 72 polymorphisms on tumour response based on MRI and pathologic response to neoadjuvant chemotherapy in locally advanced breast cancer. 
Table 1: Clinicopathological characteristics of patients across p53 variant genotypes

\begin{tabular}{|c|c|c|c|c|c|c|c|c|}
\hline & \multirow{2}{*}{$\begin{array}{c}\text { Total } \\
\mathrm{n}=170 \\
0 \\
\mathrm{n}\end{array}$} & \multicolumn{2}{|c|}{$\begin{array}{c}\mathrm{GG} \\
\mathrm{n}=72\end{array}$} & \multicolumn{2}{|c|}{$\begin{array}{c}G C \\
n=73\end{array}$} & \multicolumn{2}{|c|}{$\begin{array}{c}C C \\
n=25\end{array}$} & \multirow[t]{2}{*}{$p$} \\
\hline & & $\mathrm{n}$ & $(\%)$ & $\mathrm{n}$ & $(\%)$ & $\mathrm{n}$ & $(\%)$ & \\
\hline \multicolumn{9}{|l|}{ Menopausal status } \\
\hline Premenopausal & 62 & 28 & 37.9 & 26 & 37.62 & 8 & 32 & 0.8904 \\
\hline Postmenopausal & 108 & 44 & 61.1 & 47 & 67.38 & 17 & 68 & \\
\hline \multicolumn{9}{|l|}{ Tumor Grade } \\
\hline Grade 1 & 20 & 11 & 15.28 & 9 & 12.33 & 0 & 0 & 0.3265 \\
\hline Grade 2 & 127 & 52 & 72.22 & 53 & 72.60 & 22 & 88 & \\
\hline Grade 3 & 23 & 9 & 12.50 & 11 & 15.07 & 3 & 12 & \\
\hline \multicolumn{9}{|l|}{ Tumor size } \\
\hline $\mathrm{T} 3$ & 107 & 42 & 58.33 & 50 & 68.49 & 15 & 60 & 0.4247 \\
\hline $\mathrm{T} 4$ & 63 & 30 & 41.67 & 23 & 31.51 & 10 & 40 & \\
\hline \multicolumn{9}{|l|}{ Lymph node } \\
\hline 0 & 44 & 16 & 22.22 & 24 & 32.88 & 4 & 16 & 0.1623 \\
\hline 1 to 3 & 126 & 56 & 77.78 & 49 & 67.12 & 21 & 84 & \\
\hline \multicolumn{9}{|l|}{ Stage } \\
\hline II & 39 & 14 & 19.44 & 22 & 38.14 & 3 & 12 & 0.1148 \\
\hline III & 131 & 58 & 80.56 & 51 & 69.86 & 22 & 88 & \\
\hline \multicolumn{9}{|l|}{ ER status } \\
\hline Negative & 89 & 37 & 51.39 & 38 & 52.05 & 14 & 56 & 0.9218 \\
\hline Positive & 81 & 35 & 48.61 & 35 & 47.95 & 11 & 44 & \\
\hline \multicolumn{9}{|l|}{ PR status } \\
\hline Negative & 108 & 42 & 58.33 & 49 & 67.12 & 17 & 68 & 0.4815 \\
\hline Positive & 62 & 30 & 41.67 & 24 & 32.88 & 8 & 32 & \\
\hline \multicolumn{9}{|l|}{ Her2/neu } \\
\hline Negative & 69 & 29 & 40.28 & 28 & 38.36 & 12 & 48 & 0.6966 \\
\hline Positive & 101 & 43 & 59.72 & 45 & 61.64 & 13 & 52 & \\
\hline
\end{tabular}

Table 2: Association of p53 72 codon polymorphism and tumour response

\begin{tabular}{|c|c|c|c|c|c|c|}
\hline \multirow[t]{2}{*}{ Genotype } & \multicolumn{2}{|c|}{ Responders } & \multicolumn{2}{|c|}{ Non-responders } & \multirow[t]{2}{*}{$p$-value } & \multirow[b]{2}{*}{$\begin{array}{l}\text { RR } \\
\text { (C.I) }\end{array}$} \\
\hline & $\begin{array}{c}C R \\
n=45(\%)\end{array}$ & $\begin{array}{c}P R \\
n=88(\%)\end{array}$ & $\begin{array}{c}S D \\
n=8(\%)\end{array}$ & $\begin{array}{c}P D \\
n=4(\%)\end{array}$ & & \\
\hline \multicolumn{7}{|l|}{ TP53 } \\
\hline GG & $20(44.4)$ & $35(39.8)$ & $1(12.5)$ & $2(50)$ & & \\
\hline CG & $23(51.2)$ & $37(42)$ & $5(62.5)$ & $2(50)$ & 0.221 & - \\
\hline CC & $2(4.4)$ & $16(18.2)$ & $2(25)$ & $0(0)$ & & \\
\hline GG & $55(14)$ & $3(17)$ & & & 0.363 & 1.058 \\
\hline $\mathrm{CG}+\mathrm{CCa}$ & $78(86)$ & $9(83)$ & & & & $(0.9634-1.161)$ \\
\hline $\mathrm{CC}$ & $18(13.6)$ & & $2(17)$ & & 0.6717 & 0.9783 \\
\hline $\mathrm{CG}+\mathrm{GGa}$ & $115(86.4)$ & & $10(83)$ & & & $(0.8378-1.142)$ \\
\hline
\end{tabular}

Among the 170 breast cancer cases who were genotyped, the genotype frequencies were 72 p53Arg72Arg (42\%), p53Arg72pro (43\%), and 25 p53Arg72pro (15\%) respectively. The allele frequencies of p53 codon 72 polymorphism were 0.41 for the $\mathrm{G}$ allele and 0.36 for $\mathrm{C}$ allele. The observed genotype frequencies were in Hardy-Weinberg Equilibrium. We have analysed for the differences in clinical characteristics among geno- types. We observed no statistically significant association between the genotypes and clinicopathological characteristics such as menopausal status, histologic type, tumor grade tumor size, lymph node status and hormonal receptors (Table 1). The association of breast cancer pathologic features and p53 genotypes findings were erratic. Studies had reported that the p5372 CC homozygotes were often seen with grade 1 
Table 3: Association of $p 5372$ codon polymorphism with complete response

\begin{tabular}{ccccc}
\hline Genotype & \multicolumn{2}{c}{ MRI response } & p-value & \\
\cline { 2 - 3 } & $\begin{array}{c}\text { Complete } \\
(\mathbf{n}=45)\end{array}$ & $\begin{array}{c}\text { Partial } \\
(\mathbf{n}=88)\end{array}$ & & $\begin{array}{c}\text { RR } \\
\text { (C.I) }\end{array}$ \\
\hline TP53 & & & & \\
GG & $20(44.4)$ & $35(18.2)$ & & \\
CG & $23(51.2)$ & $37(42)$ & 0.08 & \\
CC & $2(4.4)$ & $16(39.8)$ & & 1.135 \\
GG & $20(44)$ & $35(40)$ & 0.710 & $0.8754-1.194)$ \\
CG+CCa & $25(56)$ & $53(60)$ & & 0.2972 \\
CC & $2(4)$ & $16(18)$ & 0.032 & $(0.0787-1.122)$ \\
CG+GGa & & & & \\
\hline
\end{tabular}

\begin{tabular}{|c|c|c|c|c|}
\hline \multirow[t]{2}{*}{ Genotype } & \multicolumn{2}{|c|}{ Pathological response } & \multirow[t]{2}{*}{ p-value } & \multirow[b]{2}{*}{$\begin{array}{l}\mathrm{RR} \\
\text { (C.I) }\end{array}$} \\
\hline & $\begin{array}{c}\text { PCR } \\
(n=48)\end{array}$ & $\begin{array}{l}\text { No PCR } \\
(n=104)\end{array}$ & & \\
\hline \multicolumn{5}{|l|}{ TP53 } \\
\hline GG & $23(48)$ & $41(40)$ & & \\
\hline \multirow{2}{*}{$\begin{array}{l}\text { CG } \\
\mathrm{CC}\end{array}$} & $21(44)$ & $46(44)$ & 0.3516 & - \\
\hline & $4(8)$ & $17(16)$ & & \\
\hline GG & $23(48)$ & $41(40)$ & 0.3781 & 1.265 \\
\hline $\mathrm{CG}+\mathrm{CCa}$ & $25(52)$ & $63(60)$ & & $(0.7938-2.016)$ \\
\hline $\mathrm{CC}$ & $4(8)$ & $17(16)$ & 0.2155 & 0.5671 \\
\hline $\mathrm{CG}+\mathrm{GG}^{\mathrm{a}}$ & $44(92)$ & $87(84)$ & & $(0.2273-1.415)$ \\
\hline
\end{tabular}

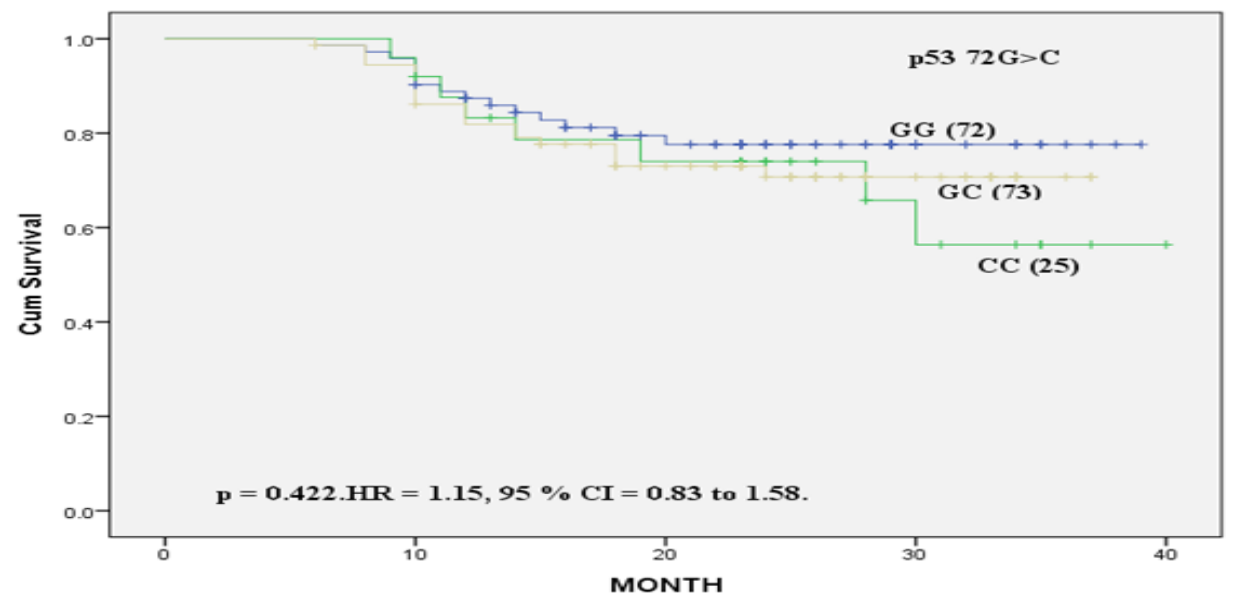

Figure 1: Kaplan-Meier curves showing progression free survival for breast cancer patients according to $\mathrm{p} 53$ variant $(72 \mathrm{G}>\mathrm{C})$.

tumors and involvement of positive axillary lymph node status. ${ }^{20,21}$ The reason for the p53 $72 \mathrm{G}>\mathrm{C}$ genotypes association with certain clinical, and pathologic features of breast cancer are currently unknown. In this study p53 codon, 72 polymorphisms variants were not significantly different between responders and non-responders. Similarly comparing genotypes of the patients having the pathological complete response and not achieving complete response were not found to be significant. How- ever, there is an association between genotype and response between patients having a complete and partial response in the recessive genetic model ( $R R=0.2972$, C.I $=0.078-1.122$ ). $95 \%$ of patients harbouring GG or CG genotypes were found to achieve complete response whereas only $5 \%$ harbouring CC genotype had achieved the complete response. Xu Ye et $a l^{21}$ reported when comparing the sensitivity of anthracycline-based treatment of patients having the Pro/Pro variant with the patients hav- 


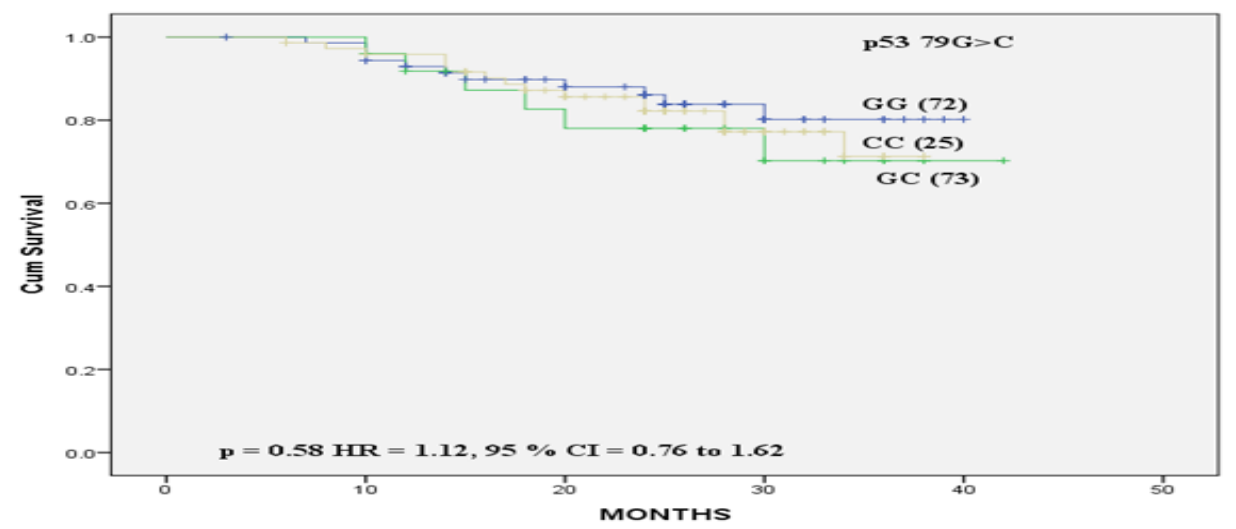

Figure 2: Kaplan-Meier curves showing Overall survival for breast cancer patients according to $\mathrm{p} 53$ variant $(72 \mathrm{G}>\mathrm{C})$.

ing the Pro/Arg or Arg/Arg variant, patients who were harboring the pro/pro variant were less sensitive. Our results are in agreement with this study. To the best of our knowledge, no studies have reported the predictive role of the $55372 \mathrm{G}>\mathrm{C}$ polymorphisms in response to neoadjuvant chemotherapy in South Indian population. We are the first to report the predictive role of p53 codon polymorphism in our South Indian population. An in vitro study showed that doxorubicin, 5-FU, and cisplatin-induced the apoptosis in human H1299 cells which have the Arg/Arg genotype than the Pro/Pro genotype. In a study it reported that, doxorubicin and cisplatin drugs were more cytotoxic to cells expressing the Arg variant. ${ }^{18}$ Our data are in agreement with this study. In our study the survival analysis of patients shown that there is no association between the genotypes and progression-free survival $(\mathrm{HR}=1.15,95 \% \mathrm{CI}$ $=0.83$ to $1.58, \mathrm{p}=0.422)$ and overall survival $(\mathrm{HR}=1.12,95 \% \mathrm{CI}=0.76$ to $1.62, \mathrm{p}=0.58$ ). There was no noticeable difference in mean survival time of PFS and OS time between genotypes. In contrast to our study in Japanese breast cancer patients of Pro/Pro genotype having worst disease free survival. ${ }^{22}$ Similarly, the Finnish study implicated the role of Pro/ Pro genotype of p53 in poorer disease free survival. ${ }^{20}$ Similarly, the p53 72 Pro allele was associated with bad prognosis in the ovarian cancer patients. ${ }^{23}$ In our study, the p53 72 codon $72 \mathrm{G}>\mathrm{C}$ polymorphism was predictive of complete tumour response of anthracycline-based chemotherapy. However, there is no association with progression-free survival and overall survival. This noticeable difference may be due to the minimal follow-up period. The mean overall survival and progression-free survival of our study are 36 and 33 months compared to other studies having the long follow-up. The present study is sufficiently powered to show p53 72G $>$ C polymorphism association with the complete response in patients harbouring Arg/Arg variant.

\section{CONCLUSION}

In the present study, our results showed that p53 $72 \mathrm{G}>\mathrm{C}$ polymorphism Partially predicts the response to neoadjuvant chemotherapy with the Arg/Arg variant patients achieve better complete response. However, this genotype had no association with overall survival and progressionfree survival.

\section{ACKNOWLEDGEMENT}

We acknowledge ICMR and JIPMER(Intramural) for funding the study

\section{CONFLICT OF INTEREST}

There is no conflict of interest in this study

\section{ABBREVIATION USED}

GCSF: Granulocyte colony stimulating factor; MRI: Magnetic resonance imaging; SNP: Single nucleotide polymorphism.

\section{REFERENCES}

1. National Cancer Registry Programme. Consolidated report of the population based cancer registries1990-1996. New Delhi: Indian Council of Medical Research; 2001.

2. Kaur H, Saini S, Peer S, Singh J. Current Therapies and Novel Targets in Treatment of Breast Cancer. Sys Rev Pharm. 2010;1(1):40-9.

3. Ellis PA, Smith IE, Detre S, Burton SA, Salter J, A'Hern R, et al. Reduced apoptosis and proliferation and increased $\mathrm{Bcl}-2$ in residual breast cancer following preoperative chemotherapy. Breast Cancer Res Treat. 1998;48(2):107-16.

4. Ellis P, Smith I, Ashley S, Walsh G, Ebbs S, Baum M, et al. Clinical prognostic and predictive factors for primary chemotherapy in operable breast cancer. J Clin Oncol. 1998;16(1):107-14.

5. Kuerer HM, Newman LA, Smith TL, Ames FC, Hunt KK, Dhingra K, et al. Clinical course of breast cancer patients with complete pathologic primary tumor and axillary lymph node response to doxorubicin-based neoadjuvant chemotherapy. $J$ Clin Onco. 1999;17(2):460-9.

6. Fisher B1, Bryant J, Wolmark N, Mamounas E, Brown A. Fisher ER, et al. Effect of preoperative chemotherapy on the outcome of women with operable breast cancer. J Clin Oncol. 1998;16(8):2672-85.

7. Bellamy CO. p53 and apoptosis. Br Med Bull. 1997;53(3):522-38.

8. Harris CC. Structure and function of the p53 tumor suppresser gene: clues for rational cancer therapeutic strategies. J Natl Cancer Inst. 1996;88(20):1442-55.

9. Silvestrini R1, Veneroni S, Benini E, Daidone MG, Luisi A, Leutner M, et al. Expression of p53, gluthathione, S-transferase-p, and Bcl-2 proteins and benefit from adjuvant radiotherapy in breast cancer. J Natl Cancer Inst.1997;89(9):63945

10. Niskanen E1, Blomqvist C, Franssila K, Hietanen P, Wasenius VM. Predictive value of c-erbB-2, p53, cathepsin-D, and histology of the primary tumor in metastatic breast cancer. Br J Oncol. 1997:76(7):917-22.

11. .Greenblatt MS, Bennett WP, Hollstein M, Harris CC. Mutations in the p53 tumor suppressor gene: clues to cancer etiology and molecular pathogenesis. Cancer Res. 1994;54(18):4855-78.

12. Soussi T, Dehouche K, Beroud C. p53 website and analysis of p53 gene mutations in human cancer: forging a link between epidemiology and carcinogenesis. Hum Mutat. 2000;15(1):105-13

13. Matlashewski GJ, Tuck S, Pim D, Lamb P, Schneider J, Crawford LV et al. Primary structure polymorphism at amino acid residue 72 of human p53. Mol Cell Biol. 1987;7(2):961-3.

14. Rosenthal AN, Ryan A Al-Jehani RM, Storey A Harwood CA Jacobs IJ et al. p53 codon 72 polymorphism and risk of cervical cancer in UK. Lancet. 1998;352(9131):871-2.

15. Storey A1, Thomas M, Kalita A, Harwood C, Gardiol D, Mantovani F, et al. Role 
of a p53 polymorphism in the development of human papillomavirus-associated cancer. Nature. 1998;393(6682):229-34

16. Dumont P, Leu JI, Della Pietra AC III, George DL, Murphy M. The codon 72 polymorphic variants of p53 have markedly different apoptotic potential. Nat Genet. 2003;33(3):357-65.

17. Pim D, Banks L. p53 polymorphic variants at codon 72 exert different effects on cell cycle progression. Int J Cancer. 2004;108(2):196-9.

18. Sullivan A1, Syed N, Gasco M, Bergamaschi D, Trigiante G, Attard M, et al. Polymorphism in wild-type $\mathrm{p} 53$ modulates response to chemotherapy in vitro and in vivo. Oncogene. 2004; 23(19):3328-37.

19. Sailaja K, Rao VR, Yadav S, Reddy RR, Surekha D, Rao DN, et al. Intronic SNPs of TP53 gene in chronic myeloid leukemia: Impact on drug response. J Nat Sci Biol Med. 2012;3(2):182-5.
20. Tommiska J, Eerola H, Heinonen M, Salonen L, Kaare M, Tallila J, et al. Breast cancer patients with p53 pro72 homozygous genotype have a poorer survival. Clin Cancer Res. 2005;11(14):5098-103.

21. Xu Y, Yao L, Ouyang T, Li J, Wang T, Fan Z, et al. p53 Codon 72 polymorphism predicts the pathologic response to neoadjuvant chemotherapy in patients with breast cancer. Clin Cancer Res. 2005;11(20):7328-33.

22. Toyama T1, Zhang Z, Nishio M, Hamaguchi M, Kondo N, Iwase H, et al. Association of TP53 codon 72 polymorphism and the outcome of adjuvant therapy in breast cancer patients. Breast Cancer Res. 2007;9(3):R34.

23. Santos AM, Sousa H, Portela C, Pereira D, Pinto D, Catarino R, et al. TP53 and P21 polymorphisms: response to cisplatinum/paclitaxel-based chemotherapy in ovarian cancer. Biochem Biophys Res Commun. 2006;340(1):256-62.

Article History: Gopinath S, Shewade DG, Dubashi B, Kadambari D, Ramesh A, Kesavan R. Effect of p53 Codon 72 Polymorphism on Clinical Outcome in Locally Advanced Breast Cancer Patients Receiving Anthracycline Based Neoadjuvant Chemotherapy. J Young Pharm. 2017;9(1):114-9. 